\title{
Combined Treatment with Buserelin+Cabergoline in Patient with Prostate Cancer and Pituitary Macroprolactinoma
}

\author{
Mihály Gervain $^{1}$, Erika Vörös ${ }^{2}$, Andor H. Molnár ${ }^{3}$, Gyöngyi Karcsú-Kis ${ }^{3}$, Ferenc Lászlón ${ }^{3}$ \\ Ferenc A. Lászlón ${ }^{3}$
}

${ }^{1}$ Department of Urology, City Hospital, Orosháza, Hungary; ${ }^{2}$ Euromedic Diagnostics, Szeged, Hungary; ${ }^{3}$ Department of Physiology, Anatomy and Neurosciences, University of Szeged, Szeged, Hungary.

Email: laszlo.a.ferenc@freemail.hu

Received June 28 $8^{\text {th }}, 2010$; revised August $1^{\text {st }}, 2010$; accepted September $5^{\text {th }}, 2010$.

\begin{abstract}
Twelve years following hemicolectomy for colon adenocarcinoma, a 75-year-old patient with prostate cancer was treated for 4 weeks with the antiandrogen nilutamide and then with the long-acting GnRH agonist buserelin. The serum testosterone and prostate-specific antigen levels had decreased dramatically after 3 months of treatment. After 2 years of buserelin administration, the hormonal state was examined. Serum estradiol, testosterone, DHEA, DHEAS, FSH and LH levels proved to be suppressed, but the serum PRL concentration was extremely high (3 $365 \mathrm{mIU} / \mathrm{l})$. The pituitary MRI revealed a macroadenoma. The patient was treated with the dopamine agonist cabergoline, together with buserelin. After 9 months of this combined treatment, the prostate-specific antigen and testosterone levels were very low; the serum estradiol, DHEA, DHEAS, FSH and LH concentrations remained suppressed. The serum PRL level fell dramatically to $6.95 \mathrm{mIU} / \mathrm{l}$, and a significant reduction in tumor size was observed on MRI. In conclusion: Combined buserelin + cabergoline treatment proved a highly successful procedure to cure this patient with prostate carcinoma and subsequent pituitary macroprolactinoma.
\end{abstract}

Keywords: Prostate cancer, Prolactinoma, Buserelin; Cabergoline

\section{Introduction}

It has long been known that prostate cancer displays an androgen sensitivity [1], and the different treatments of prostate cancer are based on the blockade of androgen production. This can be achieved by surgical castration $[2,3]$ or by chemical or hormonal suppression of the androgens. Initially, stilbestrol was administered, with moderate success, but with significant side-effects [4]; later, treatment with the steroidal antiandrogen cyproterone acetate [4] or the nonsteroidal flutamide [5] was introduced.

In 1983, a new potent luteinizing hormone releasing hormone analog was synthetized: [D-Ser $\left.\left(\mathrm{Bu}^{t}\right)^{6}\right] \mathrm{LHRH}-$ (1-9) nonapeptide ethylamide (busereline, BUS) [6,7]. Treatment with BUS greatly reduced the serum testosterone and prostate-specific antigen (PSA) levels [8]. The rate of production of testosterone was lowered to values comparable to those observed after bilateral orchidec- tomy [10]. Chronic treatment of prostate carcinoma with BUS, generally in patients with advanced metastatic prostate cancer, was reported to be a safe, nontoxic and effective form of palliation [8,9].

The prolonged administration of BUS blocks gonadotropin release and thereby achieves the effective suppression of gonadal steroidogenesis [7]. There is no uniform opinion in the relevant literature as concerns the possible changes in prolactin (PRL) secretion following BUS treatment: unchanged or decreased [10,11] and increased [12] PRL levels have all been observed. The various changes in PRL secretion following BUS treatment may be explained by differences in individual sensitivity, in the doses of BUS applied, in the duration of treatment, etc. Grotas and Nagler described the case of an 87-year-old man with prostate adenocarcinoma who had high PRL levels and a pituitary macroadenoma [13].

The present paper reports on a case with prostate cancer treated with BUS, the development of prolactinoma 
after 3 years of BUS administration, and the effects of combined BUS + cabergoline (CAB) treatment.

\section{Case Report}

In 1997, a 63-year-old man underwent a hemicolectomy because of colon adenocarcinoma (Grade: I. Dukes B2). Neither regional nor systemic metastases were detected. No X-ray or cytostatic treatment was given postoperatively. The patient was regularly controlled by colonoscopy, abdominal ultrasonography, whole-body isotope examinations and serum carcinogenic antigen (CEA) concentration determinations. No recurrence or metastasis of the colon carcinoma was observed during the subsequent 12-year period. Besides the serum CEA, the serum PSA level was also determined (Figure 1), which gradually increased from the normal range $(3.00 \mu \mathrm{g} / \mathrm{ml})$ in 2000 to above the critical level $(10.74 \mu \mathrm{g} / \mathrm{ml})$ in 2005 . The pituitary, testicular and adrenal androgen levels and thyroid function were normal. In 2005, transrectal ultrasound-guided prostate needle biopsy revealed a Gleason 1 prostate adenocarcinoma (Figure 2). The immunohistochemical examination confirmed the presence of the carcinoma. The absence of the cytokeratin-5 positive basal cell layer and a significant increase in the levels of the p504S racemase enzyme supported the diagnosis of carcinoma (Figure 3). Following a 4-week course of nilutamide treatment $(300 \mathrm{mg} / \mathrm{d}$, Anandron, Sanofi-Aventis, Paris, France), a BUS injection cure was commenced (Suprefact Depot, Sanofi-Aventis, Paris, France; $6.30 \mathrm{mg}$ at 2-month intervals), and this treatment was continued during the next 2 years. The PSA and testosterone levels dropped to $<0.003 \mu \mathrm{g}$ and $<0.07 \mathrm{nmol} / 1$ immediately following the initiation of BUS administration, and as side-effect impotence developed. It is noteworthy that the patient earlier had essential hypertension (BP: 190/110 mmHg), which was treated with antihypertensive drugs (betaxolol $20 \mathrm{mg}+$ indapamide $1.5 \mathrm{mg}$ in the morning and doxazosin $4 \mathrm{mg}+$ amlodipin $5 \mathrm{mg}$ in the evening), and the blood pressure rapidly normalized. However, when the combined antiandrogen treatment was started, the blood pressure fell dramatically (80/45 $\mathrm{mmHg}$ ) and severe hypotension developed. Accordingly, the antihypertensive treatment was considerably moderated (betaxolol $20 \mathrm{mg}+$ amlodipin $5 \mathrm{mg} / \mathrm{d}$ ), after which the general circulation became stable and the antiandrogen treatment was continued. After 2 years of BUS treatment, the hormonal state (Table 1) revealed that the thyroid function (TSH, $\mathrm{FT}_{4}, \mathrm{FT}_{3}$ ) and $\mathrm{SHBG}, \mathrm{ACTH}$, cortisol and hGH levels were normal. The serum estradiol, testosterone, DHEA, DHEAS, FSH and LH concentrations proved to be suppressed. Surprisingly, the serum PRL concentration was extremely high (3 365 $\mathrm{mIU} / \mathrm{l})$.
Table 1. Serum hormone levels after 2 years of buserelin treatment (Changes: Ø: unchanged; $\downarrow$ : decreased; $\downarrow \downarrow$ : significantly decreased; $\uparrow \uparrow \uparrow$ : highly significantly increased).

\begin{tabular}{cccc}
\hline & & Changes & Ref. range \\
\hline TSH & $3.19 \mathrm{mIU} / 1$ & $\varnothing$ & $0.27-4.2$ \\
$\mathrm{FT}_{4}$ & $12.61 \mathrm{pmol} / 1$ & $\varnothing$ & $12-22$ \\
$\mathrm{FT}_{3}$ & $4.47 \mathrm{pmol} / 1$ & $\varnothing$ & $3.1-6.8$ \\
Estradiol & $<18.4 \mathrm{pmol} / 1$ & $\downarrow$ & $28-156$ \\
Testosterone & $<0.07 \mathrm{nmol} / 1$ & $\downarrow \downarrow$ & $9.9-27.8$ \\
SHBG & $33.7 \mathrm{nmol} / 1$ & $\varnothing$ & $13.0-71.0$ \\
$\mathrm{ACTH}$ & $3.11 \mathrm{pmol} / 1$ & $\varnothing$ & $1.1-10.12(8 \mathrm{~h})$ \\
Cortisol & $348 \mathrm{nmol} / 1$ & $\varnothing$ & $171-536(8 \mathrm{~h})$ \\
DHEA & $3.2 \mathrm{nmol} / 1$ & $\downarrow$ & $8.5-36$ \\
DHEAS & $0.17 \mu \mathrm{mol} / 1$ & $\downarrow$ & $0.44-3.34$ \\
$\mathrm{FSH}$ & $0.85 \mathrm{IU} / 1$ & $\downarrow$ & $1.50-12.40$ \\
$\mathrm{LH}$ & $0.10 \mathrm{IU} / 1$ & $\downarrow \downarrow$ & $1.70-8.60$ \\
$\mathrm{PRL}$ & $3365 \mathrm{mIU} / 1$ & $\uparrow \uparrow \uparrow$ & $86-324$ \\
$\mathrm{hGH}$ & $0.34 \mu \mathrm{g} / \mathrm{ml}$ & $\varnothing$ & $0.01-1.0$ \\
\hline
\end{tabular}

Radiologic assessment of the pituitary was performed in the International Diagnostic Centre, Szeged, in 2009. The MRI protocol consisted of sagittal and coronal T1-weighted images. All scans were read by one neuroradiologist (EV). The MRI demonstrated a pituitary macroadenoma measuring $0.8 \mathrm{~cm} \times 1.2 \mathrm{~cm}$ (Figure 4(a)). No visual field defects or neurologic symptoms were observed. The patient was treated with $\mathrm{CAB}(2 \times 0.5$ $\mathrm{mg} /$ week) together with BUS. After 5 months of this combined treatment, the PSA and testosterone levels were very low; while the estradiol, DHEA, DHEAS and FSH levels proved to be unchangingly suppressed and the serum PRL concentration had fallen dramatically to $6.95 \mathrm{mIU} / \mathrm{l}$, with no significant change a further 2 months later $(6.51 \mathrm{mIU} / \mathrm{l})$. Repeated MRI demonstrated a reduction in tumor size (about 50\%) (Figure 4(b)). The dose of CAB was decreased $(1 \times 0.5 \mathrm{mg} /$ week $)$, and 2 months later the serum PRL level remained very low (9.95 $\mathrm{mIU} / \mathrm{l})$.

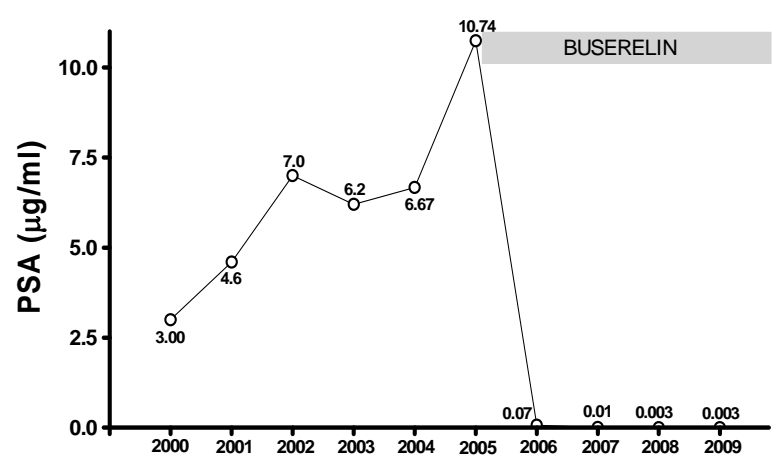

Figure 1. The serum prostate-specific antigen (PSA) level before and after treatment with buserelin. 


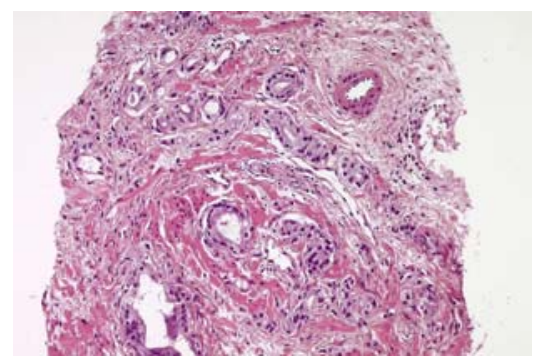

Figure 2. Histological examination of prostatic tissue cylinder (hematoxilin-eosin staining).

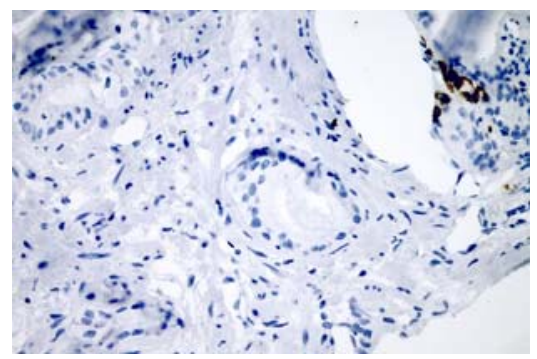

Figure 3 . The immunohistochemical examination of prostatic tissue cylinder.

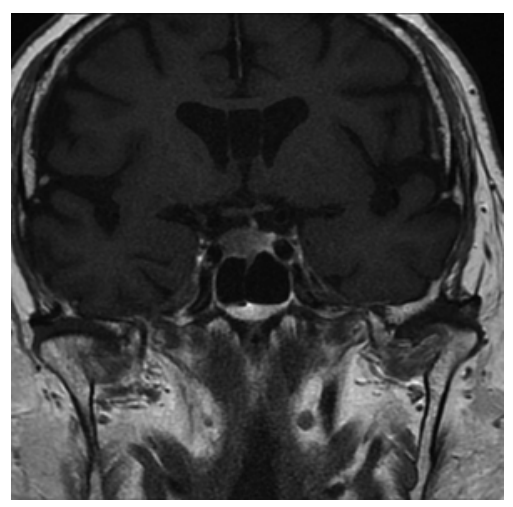

(a) Before the cabergoline administration.

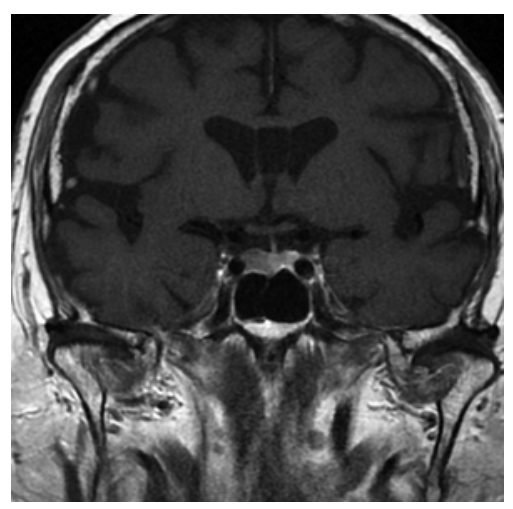

(b) After 9 months cabergoline treatment.

Figure 4 .Pituitary MR examination.

\section{Discussion}

Numerous data have been published on the relationship between PRL secretion and the prostatic function in animal experiments. PRL has been stated to play a significant role in the growth of the prostate in rodents. In contrast, Robertson et al. (2003) did not find any correlation between hyperprolactinemia and prostate carcinogenesis in PRL receptor knockout mice[14]. However, the whole pituitary function is important in this respect: hypophysectomy induced greater degree of atrophy in the rat prostate comparable to the effect of castration [15].

Chronic treatment with the gonadotropin-releasing analog BUS blocks gonadotropin secretion and at the same time effectively suppresses gonadal steroidogenesis [8]. It is somewhat surprising that the very low testosterone secretion during BUS treatment does not induce increased FSH or LH release because of the feedback regulation. The mode of action of this compound is not yet fully explained.

The androgens that arise from the adrenals include the inactive steroids androstenedione, dehydroepiandrosterone (DHEA) and DHEA sulphate (DHEAS), which are metabolized to testosterone and dihydrotestosterone in the prostate itself [16]. BUS suppresses the testicular androgens, but does not inhibit adrenal androgen production [17]. Combined androgen blockade involving a receptor-blocking antiandrogen with BUS led to results that were superior to those of treatment with BUS alone [16].

In our case, the most important problem was how to modify the treatment because of the severe hyperprolactinemia. The strong argument in favor of BUS treatment continuation is the persistence of prostate cancer. However, the introduction of specific hyperprolactinemia treatment cannot be avoided. Supplementation of the BUS treatment with a PRL-reducing agent was supported when the prolactinoma was discovered by MRI as the source of the high PRL level. The prolactinoma is the most common subtype of active, hormone-secreting pituitary adenoma. Dopamine agonists are highly effective in normalizing hyperprolactinemia and decreasing the tumor size in patients with prolactinoma. CAB is a new, potent, selective and long-acting dopamine agonist which blocks PRL secretion. Reports on long-term CAB treatment, indicated that it was better tolerated [18] than bromocriptine and side-effects seldom developed. Delgrange et al. (2009) [19] described the normalization of high PRL levels in (96\% of their cases) and significant tumor shrinkage (in 82\%) during $\mathrm{CAB}$ administration to 122 patients with macroprolactinoma. In our case, the starting dose of $\mathrm{CAB}$ was $0.5 \mathrm{mg}$ twice weekly, and after treatment for 5 months the serum PRL concentration had 
fallen to $6.95 \mathrm{mIU} / \mathrm{l}$ and significant tumor shrinkage was observed on MRI. Finally, the dose of CAB was reduced to $0.5 \mathrm{mg} /$ week.

As an unpleasant side-effect, severe hypotension, developed immediately after the introduction of antiandrogen therapy. We earlier observed that androgens are able to increase the sensitivity of blood vessels to vasoconstriction induced by different vasoactive agents (e.g. vasopressin), and antiandrogen compounds (cyproterone acetate or flutamide) can prevent this effect of androgens [20]. Hypotension induced by antiandrogen administration is not a well-known side-effect, and attention should be drawn to this important aspect. At the beginning of antiandrogen therapy, we have to control the blood pressure frequently, and if necessary to reduce the doses of antihypertensive drugs.

In conclusion: The combined treatment with BUS + $\mathrm{CAB}$ proved to be a highly successful procedure in this patient with prostate adenocarcinoma and pituitary macroprolactinoma. The minimal length of $\mathrm{CAB}$ treatment recommended by The Pituitary Society is $1-3$ years [21].

\section{REFERENCES}

[1] C. Huggins and C. V. Hodges, "Studies on Prostatic Cancer. I. The Effect of Castration on Serum Phosphatases in Metastatic Carcinoma of the Prostate," Cancer Research, Vol. 1, No. 1941, pp. 293-296.

[2] C. E. Blackard, D. P. Byar and W. P. Jordan, Jr., "Orchidectomy for Advanced Prostatic Carcinoma. A Reevaluation," Urology, Vol. 1, No. 6, 1973, pp. 553-560.

[3] F. Sciarra, G. Sorcini, F. Di Silverio and V. Gagliardi, "Plasma Testosterone and Androstenedione after Orchiectomy in Prostatic Adenocarcinoma," Clinical Endocrinology (Oxford), Vol. 2, No. 2, 1973, pp. 101-109.

[4] H. J. de Voogt, P. H. Smith, M. Pavone-Macaluso, M. de Pauw and S. Suciu, "Cardiovascular Side Effects of Diethylstilbestrol, Cyproterone Acetate, Medroxyprogesterone Acetate and Estramustine Phosphate Used for the Treatment of Advanced Prostatic Cancer: Results from European Organization for Research on Treatment of Cancer Trials 30761 and 30762," The Journal of Urology, Vol. 135, No. 2, 1986, pp. 303-307.

[5] R. A. Airhart, T. F. Barnett, J. W. Sullivan, R. L. Levine and J. U. Schlegel, "Flutamide Therapy for Carcinoma of the Prostate," Southern Medical Journal, Vol. 71, No. 7, 1978, pp. 798-801.

[6] G. Tolis, N. Faure, M. Koutsilieris, A. Lemay, S. Klioze, A. Yakabow and A. T. Fazekas, "Suppression of Testicular Steroidogenesis by the GnRH Agonistic Analogue Buserelin (HOE-766) in Patients with Prostatic Cancer: Studies in Relation to Dose and Route of Administration," Journal of Steroid Biochemistry, Vol. 19, No. 1C, 1983, pp. 995-998.
[7] J. Trachtenberg, "The Treatment of Metastatic Prostatic Cancer with a Potent Luteinizing Hormone Releasing Hormone Analogue," The Journal of Urology, Vol. 129, No. 6, 1983, pp. 1149-1152.

[8] G. Mathe, A. V. Schally, A. M. Comaru-Schally, R. Y. Mauvernay, M. L. Vovan, D. Machover, J. L. Misset, B. Court, P. Bouchard, J. Duchier and et al., "Phase II Trial with D-Trp-6-LH-RH in Prostatic Carcinoma: Comparison with Other Hormonal Agents," The Prostate, Vol. 9, No. 4, 1986, pp. 327-342.

[9] H. J. de Voogt, U. Studer, F. H. Schroder, J. G. Klijn, M. de Pauw and R. Sylvester, "Maximum Androgen Blockade Using LHRH Agonist Buserelin in Combination with Short-term (two weeks) or Long-term (continuous) Cyproterone Acetate is Not Superior to Standard Androgen Deprivation in the Treatment of Advanced Prostate Cancer. Final Analysis of EORTC GU Group Trial 30843. European Organization for Research and Treatment of Cancer (EROTC) Genito-Urinary Tract Cancer Cooperative Group," European Urology, Vol. 33, No. 2, 1998, pp. 152-158.

[10] H. Parmar, R. H. Phillips, S. L. Lightman, L. Edwards, L. Allen and A. V. Schally, "Randomised Controlled Study of Orchidectomy vs Long-acting D-Trp-6-LHRH Microcapsules in Advanced Prostatic Carcinoma," Lancet, Vol. 2, No. 8466, 1985, pp. 1201-1205.

[11] J. Waxman, "Gonadotrophin Releasing Hormone Analogues for Prostatic Cancer: An Overview," Seminars in Oncology, Vol. 15, No. 4, 1988, pp. 366-370.

[12] H. Matzkin, I. Kaver, O. Lewyshon, D. Ayalon and Z. Braf, "The Role of Increased Prolactin Levels under Gnrh Analogue Treatment in Advanced Prostatic Carcinoma," Cancer, Vol. 61, No. 11, 1988, pp. 2187-2191.

[13] A. B. Grotas and H. M. Nagler, "Presentation of a Functional Pituitary Adenoma as a Significant Decrease in Prostate-Specific Antigen Level in a Patient Followed for Prostate Cancer," The Canadian Journal of Urology, Vol. 13, No. 6, 2006, pp. 3346-3347.

[14] F. G. Robertson, J. Harris, M. J. Naylor, S. R. Oakes, J. Kindblom, K. Dillner, H. Wennbo, J. Tornell, P. A. Kelly, J. Green and C. J. Ormandy, "Prostate Development and Carcinogenesis in Prolactin Receptor Knockout Mice,' Endocrinology, Vol. 144, No. 7, 2003, pp. 3196-3205.

[15] A. Peyre, J. P. Ravault and P. Laporte, "Potentiation Effect of Endogenous Prolactin on Male Sex Effectors Treated with Testosterone," Comptes rendus des séances de la Société de biologie et de ses filiales, Vol. 162, No. 8, 1968, pp. 1592-1595.

[16] F. Labrie, A. Belanger, V. Luu-The, C. Labrie, J. Simard, L. Cusan, J. Gomez and B. Candas, "Gonadotpin-releasing Hormone Agonists in the Treatment of Prostate Cancer," Endocrine Reviews, Vol. 26, No. 3, 2005, pp. 361-379.

[17] I. M. Spitz, B. Chertin, A. Fridmans, A. Farkas, A. Belanger, H. Hartman and F. Labrie, "Partial Androgen Suppression Consequent to Increased Secretion of Adre- 
nal Androgens in a Patient with Prostate Cancer Treated with Long-acting GnRH Agonists," Prostate Cancer and Prostatic Diseases, Vol. 12, No. 1, 2009, pp. 100-103.

[18] E. Ciccarelli, M. Giusti, C. Miola, F. Potenzoni, D. Sghedoni, F. Camanni and G. Giordano, "Effectiveness and Tolerability of Long Term Treatment with Cabergoline, a New Long-lasting Ergoline Derivative, in Hyperprolactinemic Patients," The Journal of Clinical Endocrinology and Metabolism, Vol. 69, No. 4, 1989, pp. 725-728.

[19] E. Delgrange, T. Daems, J. Verhelst, R. Abs and D. Maiter, "Characterization of Resistance to the Prolactin-lowering Effects of Cabergoline in Macroprolactinomas: A Study in 122 Patients," The European Journal of Endocrinology, Vol. 160, No. 5, 2009, pp. 747-752.
[20] F. A. Laszlo, C. Varga, A. Papp, I. Pavo and F. Fahrenholz, "Difference between Male and Female Rats in Vasopressor Response to Arginine Vasopressin," Acta Physiologica Hungarica, Vol. 81, No. 2, 1993, pp. 137-145.

[21] F. F. Casanueva, M. E. Molitch, J. A. Schlechte, R. Abs, V. Bonert, M. D. Bronstein, T. Brue, P. Cappabianca, A. Colao, R. Fahlbusch, H. Fideleff, M. Hadani, P. Kelly, D. Kleinberg, E. Laws, J. Marek, M. Scanlon, L. G. Sobrinho, J. A. Wass and A. Giustina, "Guidelines of the Pituitary Society for the Diagnosis and Management of Prolactinomas," Clinical Endocrinology (Oxford), Vol. 65, No. 2, 2006, pp. 265-273. 